\title{
The Relationship between Perceived Organizational Justice and OCBs with Consider Moderating Role of Equity Sensitivity: Some Cultural Implications
}

\author{
Mohesn Golparvar ${ }^{1} \&$ Zahra Javadian $^{1}$ \\ ${ }^{1}$ College of Psychology and Education, Islamic Azad University, Esfahan, Iran \\ Correspondence: Mohesn Golparvar, College of Psychology and Education, Islamic Azad University, Khorasgan \\ Branch, Esfahan, Iran. E-mail: drmgolparvar@gmail.com
}

Received: March 16, 2012 Accepted: April 5, $2012 \quad$ Published: June 1, 2012

doi:10.5539/ijps.v4n2p28

URL: http://dx.doi.org/10.5539/ijps.v4n2p28

\begin{abstract}
Perceived organizational justice is an important factor for prediction of various aspects of OCBs. This research investigates the extent to which equity sensitivity moderates the relationship between perceived organizational justice and OCBs. It was hypothesized that distributive, procedural, informational and interpersonal justice are related to OCBs (helping behavior, civic virtue, and sportsmanship) and equity sensitivity has been moderate these relationships. Research sample group were 123 employees of a petrochemical company in Iran. The moderated hierarchical regression analysis indicated that equity sensitivity moderates the relationship between perceived distributive organizational justice with civic virtue and sportsmanship. That is, in entitled group (and no in equity sensitive or benevolent groups) distributive justice positively and significantly related to civic virtue and sportsmanship $(\mathrm{P}<0.05)$. Also results indicated that equity sensitivity moderates the relationship between perceived procedural organizational justice and sportsmanship. That is, in an equity sensitive group (and no in entitled or benevolent groups) procedural justice positively and significantly related to sportsmanship $(\mathrm{P}<0.05)$.
\end{abstract}

Keywords: perceived organizational justice, OCBs, equity sensitivity

\section{Introduction}

Nowadays organizations for succession need employees who engage in extra-role behaviors such as organizational citizenship behaviors (OCBs) (Chien, 1988). During recent decades OCBs has become one of the most important variable at workplace researches (Asgari, Silong, Ahmad \& Samah, 2008). Historically, OCBs defined as discretionary behaviors that are not explicitly recognized by organization, but enhance the organizational performance by contributing to its social and psychological environment (Asgari et al, 2008). In essence, it could be said that OCBs are behaviors in which employees engage in them beyond their formal role requirements (Chien, 1988). The empirical findings suggest that OCBs are related with many individual and organization-level constructs such as organizational performance and effectiveness (Paille, 2009). Three dimensions of OCBs are helping behaviors, sportsmanship, and civic virtue (Organ \& Konovsky, 1989). Helping behaviors is being helpful to coworkers or other people with little interest in being rewarded for one's efforts. Sportsmanship is refraining from complaining about trivial matters, and civic virtue is responsible participation in the social life of the organization such as staying up-to-date with important issues of the organization (Miao \& Kim, 2010). One variable that could be possibly linked to OCBs is the perceived organizational justice (Organ \& Moorman, 1993; Podsakoff, MacKenzie, Paine \& Bachrach, 2000). In previous researches, researchers have used perceived organizational justice dimensions as antecedents of OCBs. The social exchange and equity theories suggest that OCBs are social responses to supervisors' and/or coworkers' behavior as well as a possible reaction of the individual to the behavior of his or her superior or to other motivation -based mechanisms in the workplace. Although studies have demonstrated that OCBs has a positive relationship with organizational performance (Podsakoff et al, 2000), but most OCBs studies have been conducted in the western countries (Lievens \& Anseel, 2004; Paille, 2009). In past decade, OCBs has been studied in other countries such as in Iran (Golparvar \& Rafizadeh, 2009). Research on OCBs in other countries is very important since cultural factors (Miao \& Kim, 2010) may affect the relationship between perceptual constructs such as perceived organizational justice and OCBs. 


\section{Literature Review}

\subsection{Perceived Organizational Justice and OCBs}

Organizational justice is a perceptual variable and refers to the presence of justice in distribution of outcomes, implementation of decisions and interaction between authority figures with employees in the organization (Colquitt, 2001). The research has suggested distributive, procedural, interpersonal, and informational justice as dimensions of perceived organizational justice at workplaces (e.g., Colquitt, 2001; Golparvar \& Rafizadeh, 2010). Distributive justice focuses on employees' beliefs about a mastery of justice rules in distribution of outcomes in organization, and procedural justice focuses on employees' perception about the presence of justice rules in decision making and administration of decisions at workplaces. On the other hand, interpersonal justice focuses on presence of justice in social interactions that take place between individuals and others (especially supervisors) in the organizations. Finally, informational justice focuses on just information distribution in organization and how information regarding decisions is disseminated and explained to others (Ishak \& Alam, 2009).

According to Moorman (1991), justice perceptions are important in predicting the occurrence of OCBs. From an exchange theory perspective, OCBs are means for an employee to reciprocate fair treatment from the organization (Moorman, 1991). When justice rules violated in organization, employees will likely believe that the social exchange has been violated, and accordingly respond to this justice violation in the form of decreased OCBs (Blackely, Andrews \& Moorman, 2005). Previous researches reported a positive relationship between some of perceived organizational justice dimensions and OCBs. In a meta-analysis review of 55 studies, Organ and Ryan (1995) found that perceived justice was a predictor of OCBs. Cohen-charash \& Spector (2001) in another meta- analytic study reported the positive significant relationship between interactional and procedural justice with some dimensions of OCBs. Williams, Pitre \& Zainuba (2002) reported positive significant relationship between interactional justice and OCB. The underlying mechanism about the relationship between some perceived organizational justice dimensions and some OCBs facets is that, when the organization apply the just rules at workplaces, inform to employees that they are valued by the organization. When employees perceived they are valued members of an organization, they are more likely to engage in OCBs as a form of social exchange (Eisenberger, Fasolo \& Davis-LaMastro, 1990). Also, when an organization allows its members to criticize unjust rules, ensures employees that the organization will care about their human rights (Eisenberger et al, 1990).

\subsection{Equity Sensitivity as a Moderator on the POJ-OCBs Relationship}

Equity theory emphasizes that individuals evaluate their efforts and subsequent outcomes against the efforts and subsequent outcomes of their peers (Adams, 1965). In the workplace, this theory suggests that employees compare their efforts and outcomes against their co-workers to find out whether they are being treated fairly or not. According to the equity theory, if employees encounter inequity, i.e., either they are being under - rewarded or over - rewarded, they will be motivated to restore equity (Adams, 1965). Based on the equity theory, individuals are different in terms of their preferences for equity (Huseman, Hatfield, \& Miles, 1985, 1987; King \& Miles, 1994; Foote \& Harmon, 2006). Huseman et al (1987) proposed three categories of people on the basis of sensitivity to equity: (a) benevolents, (b) equity sensitivity, and (c) entitleds or self interest group.

Hayes (2005) states that benevolents individual concern with higher work input to outcome ratio than equity sensitivity, and entitleds, thereby have a higher tolerance for being under-rewarded. Equity sensitivity concern with equity input to outcome ratio, and entitled people concern with lower input to outcome ratio (Hayes, 2005; Wheeler, 2007). Benevolent individuals easily give their skills and abilities to the organization without any expectation about fair outcomes. Unlike benevolents, entitleds emphasize on personal outcomes and have expectation about over-reward outcomes. Among benevolent and entitled people are the equity sensitivity who emphasize on having a suitable contribution to the organization and achieving fair outcomes (Huseman et al, 1985, 1987; Morrison \& Robinson, 1997; Allen, Biderman \& White, 2004).

Previous researches revealed that three equity sensitivity groups can be different in their reactions to inequity positions (King \& Miles, 1994). Huseman et al (1985) reported that, there is significant difference between benevolents and entitleds reactions to under - rewarded position. They findings revealed that benevolents have higher satisfaction than entitleds in under-reward position. Consistent with Huseman et al's (1985) study, Miles, Hatfield, and Huseman (1989, c.f, Hayes, 2005) reported the same results in another research. They also found that this three equity sensitivity groups have relatively similar attitudes about the amount of outcomes they receive but dissimilar attitudes about how much work input should be necessary (Hayes, 2005; Lok, 2007). King, Miles \& Day (1993) found that benevolents tolerance for under- rewarded is related to altruism, empathy, or 
disguised self-interest in them. For this, they redefined the concerns of benevolents and entitleds, and said benevolents have a greater tolerance for, but not preference for under-reward positions. Conversely, they reconceptualized entitleds as individuals who are intolerant of under-reward positions, and said entitleds primarily focus on self interest outcomes without their contributions in the position (Sauley \& Bedeian, 2000). In another study, King and Miles (1994) reported the positive significant relation between equity sensitivity and professional attitudes (i.e., organizational commitment, job satisfaction).

Along with above mentioned empirical findings about difference between three groups of equity sensitivity, there are empirical studies about the relationship between equity sensitivity and OCBs. It should be said that, although some researchers have not reported incremental power for equity sensitivity in prediction of OCBs beyond that satisfaction and perceived organizational justice (Konovsky \& Organ, 1996), there is some researches in which them showed that the equity sensitivity is an potential predictor for OCBs as well moderator for the relationship between perceived organizational justice and OCBs. Fok, Hartman, Patti, and Razek (1999, c.f., Blakely et al, 2005) found a significant relation between equity sensitivity and OCBs. They findings indicate that benevolent would be more likely to engage in OCBs than entitleds. Kickul and Lester (2001, c.f., Blakely et al, 2005) found that equity sensitivity moderates the relationship between psychological contract breach and OCBO. Blakely et al (2005) also found that equity sensitivity moderates the relationship between perceived organizational justice and OCBs.

Blackely et al (2005) believed that "threshold of fairness" rule is an underlying rule which can explain what happen for benevolents, equity sensitivity, and entitleds or self interest groups in reaction to fluctuation of justice in the organization or at workplaces. On the basis of this rule, fluctuating of perceived organizational justice is not important for benevolent (because they are more tolerant of unfair treatment) to engaging in OCBs, but for entitleds, perceived organizational justice is important if lead to them over-reward outcomes. Finally for equity sensitivity, perceived organizational justice is important, because brings them with fair outcomes (Blackely et al, 2005). Taken together, pervious research and theory implies that equity sensitivity could be moderate the relationship between perceived organizational justice and OCBs.

\subsection{Conceptual Model of Research and Hypotheses}

Even though the previous research shed light the theoretical foundation of linkage between perceived organizational justice and OCBs with moderating effect of equity sensitivity, there are some limitations as well. First, above mentioned researches has not used the four dimensions justice types separately in their analysis (Colquitt, Greenberg, \& Zapata-Phelan, 2005; Roch \& Shanock, 2006; Young, 2010). Using perceived organizational justice as a global measure in an investigation may not provide comprehensive understanding of underlying mechanism on the relationship between these variables with outcome variables such as OCBs. Young (2010) stated that the omission of one or two of these justice dimensions may lead researchers to overlook any significant relationship that would exist if the omitted dimensions were included (Young, 2010). Second, most of researches which referred to them in investigation such as current research has been administered in western countries (Farh, Hacket, \& Liang, 2007; Young, 2010). Nevertheless, there is growing body of researches which revealed that cultural values are very important in studying the relationship between perceptual variables (i.e., perceived organizational justice) and behavioral outcomes (i.e., OCBs) (James, 1993; Yamaguchi, 2003; Fischer \& Smith, 2003; Allen, Takeda, \& White, 2005; Restubog, Bordia \& Tang, 2007; Hollensbe, Khanzanchi \& Masterson, 2008; Young, 2010).For instance, more recent cross-cultural investigations try to obtaining a more extensive understanding about the role of individualism (i.e., the cultures in which them people have more tendency to be independent and self- interest ) and collectivism (i.e., the cultures in which them people have more tendency to collective work along with group identity) in perceived organizational justice and their behavioral outcomes such as OCBs (Fischer \& Smith, 2003). This implies that the employees' perception and their behavioral reaction to them may vary in other countries such as Iran. Finally, Blackely et al (2005) stated that further researches are needed about the moderating role of equity sensitivity on the linkage between perceived organizational justice and employees behavioral outcomes such as OCBs. In this regard, our aim was to extend current body of knowledge by testing the relationship between four dimensions of perceived organizational justice and three dimensions of OCB with considering the potential moderating effects of equity sensitivity.

\section{Hypotheses}

H1: There are positive relationships between perceived organizational justice dimensions (distributive, procedural, informational and interpersonal) and OCBs (helping behavior, civic virtue, and sportsmanship).

H2: There is positive relationship between equity sensitivity and OCBs (helping behavior, civic virtue, and 
sportsmanship).

H3: Equity sensitivity will moderate the relationship between perceived organizational justice dimensions (distributive, procedural, informational and interpersonal) and OCBs (helping behavior, civic virtue, and sportsmanship). That is, there are different relationships between perceived organizational justice dimensions and OCBs among equity sensitives, benevolents and entitleds.

H3a: Equity sensitivity will moderate the relationship between perceived distributive justice and OCB (helping behavior, civic virtue, and sportsmanship), That is, there are different relationships between perceived distributive justice and OCBs among equity sensitives, benevolents and entitleds.

$\mathrm{H} 3 \mathrm{~b}$ : Equity sensitivity will moderate the relationship between perceived procedural justice and OCB (helping behavior, civic virtue, and sportsmanship). That is, there are different relationships between perceived procedural justice and OCBs among equity sensitives, benevolents and entitleds.

H3c: Equity sensitivity will moderate the relationship between perceived informational justice and OCB (helping behavior, civic virtue, and sportsmanship). That is, there are different relationships between perceived informational justice and OCBs among equity sensitives, benevolents and entitleds.

H3d: Equity sensitivity will moderate the relationship between perceived interpersonal justice and OCB (helping behavior, civic virtue, and sportsmanship). That is, there are different relationships between perceived organizational justice dimensions and OCBs among equity sensitives, benevolents and entitleds.

The conceptual model of current research is depicted in Figure 1.

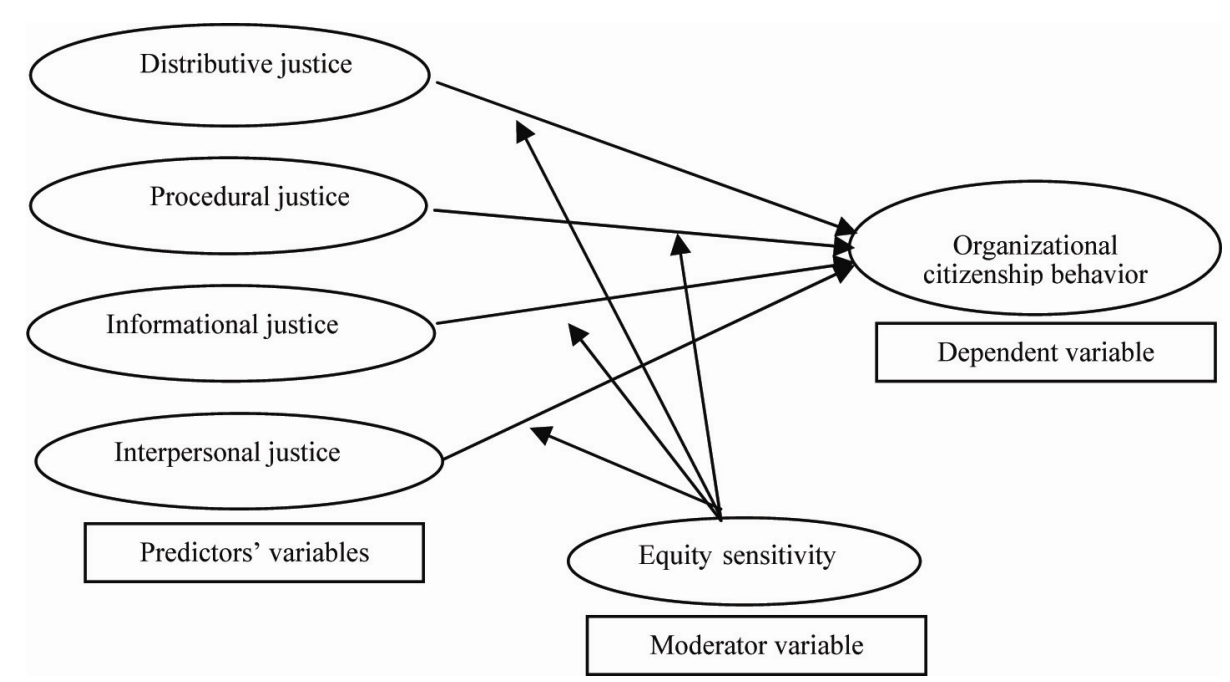

Figure 1. Conceptual model of current research

\section{Research Methodology}

\subsection{Participants}

The sample group of current research was the full time employees of a petrochemical industry in Iran. The one hundred forty questionnaires (including scales of perceived organizational justice, equity sensitivity, and OCBs) were distributed among employees. One hundred twenty three of the employees returned the questionnaires. In this regard response rate was $87.85 \%$. The mean age of the participants was 30 years with $\mathrm{SD}=7.9$. The mean organizational tenure of the participants were 6 years with $\mathrm{SD}=6.71$. Eighty-five percent $(85 \%)$ were males and fifteen percent (15\%) were females. Forty-seven percent (47\%) were single and fifty three percent $(53 \%)$ were married. Majority of the sample group had secondary studies, or university studies $(81.5 \%)$.

\subsection{Instruments}

\subsubsection{Equity Sensitivity}

Participant's equity sensitivity was assessed by Equity Sensitivity Instrument (ESI) adopted from Huseman et al (1985). This instrument measures equity sensitivity on a spectrum from entitle to benevolent. In each item, 
participants must divided 10 points between two statements. The content of one statement is about entitled tendency and the content of other statement included benevolent tendency of respondent. A sample item is "It would be more important for me to: A. Help others. B. Watch out for my own good." The 10 points assigned to each five items result in participant scores oscillate from 0 to 50.The high score in this instrument reveal the respondent is highly benevolent and low score reveal the respondent is highly entitled. These items were translated into Farsi (Iranian language) with the use of two stage translation/back translation method (Brislin, 1980). Firstly, questionnaire translated into the Farsi (Iranian language) by a bilingual native Iranian psychologist. Next, the translated Iranian version was "back translated" into English by another psychologist. Finally, the translated English version was adapted to the original version and any differences were revised trough active interaction between the two psychologists. Cronbach's alpha for the entire sample was 0.85 . Following the procedure described in Blackly et al (2005), the sample was categorized into the three groups trough trichotomizing the participants at approximately $1 / 2 \mathrm{SD}$ from the average. On the basis of this manner, those with a score of less than 3.75 being categorized as entitleds $(\mathrm{n}=20, \mathrm{M}=2.17, \mathrm{SD} .=1.31)$, those with a score of from 3.75 to 5.25 being categorized as equity sensitives $(n=70, M=4.58, S D$. $=0.45)$, and those with a score of 5.23 or greater being categorized as benevolents $(n=33, M=5.96, S D .=0.48)$.

\subsubsection{Organizational Citizenship Behaviors (OCBs)}

Participant's OCBs were measured with the 13 item scale which adopted from Ackfeldt and Coote (2005). This multi-dimensional scale consisted of helping behavior (five items, A sample item is: I give my time to help employees with work-related problems), civic virtue (four items, A sample item is: I attend work-related information sessions), and sportsmanship (four items, A sample item is: keep trivial complaints to myself), and has been translate and validated in Iranian work settings in a previous research (Golparvar \& Rafizadeh, 2009). In three scales, responses are given along a 5-point scale from $1=$ strongly disagree to $5=$ strongly agree. Cronbach's alpha for helping behavior, civic virtue, and sportsmanship in current research were $0.85,0.74$, and 0.83 respectively.

\subsubsection{Perceived Organizational Justice}

Participant's perceived organizational justice was assessed by 20 item scale adopted from Colquit (2001). The scale measures distributive justice (four items, An example item is: Does your outcome reflect the effort you have put into your work), procedural justice (seven items, An example item is: Have you been able to appeal the outcome arrived at by the decision making procedures in your organization?), interpersonal justice (four items, An example item is: Has your supervisor treated you in a polite manner), and informational justice (five items, An example item is: Has your supervisor explained the procedures thoroughly). This scale has been translate and validated at Iranian work settings in a previous research (Golparvar \& Rafizadeh, 2010). In four scales, responses are given along a 5 -point scale from $1=$ very few to $5=$ very much. Cronbach's alpha for procedural, distributive, interpersonal, and informational justice in current research were $0.79,0.72,0.76$, and 0.71 respectively.

\section{Results}

Table 1 presents the means and standard deviations for all the variables included in the study among three groups of equity sensitivity.

Table 1. Mean and standard deviation of research variables among three groups of equity sensitivity

\begin{tabular}{lccccccccc}
\hline & \multicolumn{3}{c}{ Entitleds } & \multicolumn{3}{c}{ Equity Sensitivity } & \multicolumn{3}{c}{ Benevolents } \\
& $\mathrm{N}$ & $\mathrm{M}$ & $\mathrm{SD}$ & $\mathrm{N}$ & $\mathrm{M}$ & $\mathrm{SD}$ & $\mathrm{N}$ & $\mathrm{M}$ & $\mathrm{SD}$ \\
\hline interpersonal justice & 20 & 3.02 & 0.54 & 70 & 3.3 & 0.75 & 33 & 3.21 & 0.88 \\
informational justice & 20 & 2.89 & 0.75 & 70 & 3.03 & 0.62 & 33 & 2.81 & 0.71 \\
procedural justice & 20 & 2.76 & 0.47 & 70 & 2.91 & 0.67 & 33 & 2.84 & 0.67 \\
distributive justice & 20 & 2.9 & 1.04 & 70 & 3.03 & 0.64 & 33 & 2.98 & 0.87 \\
helping behavior & 20 & 3.26 & 0.73 & 70 & 3.72 & 0.74 & 33 & 3.83 & 0.84 \\
civic virtue & 20 & 3.15 & 0.88 & 70 & 3.62 & 0.67 & 33 & 3.73 & 0.74 \\
sportsmanship & 20 & 3.28 & 1.03 & 70 & 3.65 & 0.81 & 33 & 3.82 & 0.89 \\
equity sensitivity & 20 & 2.17 & 1.31 & 70 & 4.58 & 0.45 & 33 & 5.96 & 0.48 \\
\hline
\end{tabular}

Inter-correlations, means and standard deviations for all variables for total sample of current research are reported in Table 2. 
Table 2. Mean, standard deviation and inter-correlations for study variables among total sample

\begin{tabular}{lccccccccc}
\hline & $\mathrm{M}$ & $\mathrm{SD}$ & 1 & 2 & 3 & 4 & 5 & 6 & 7 \\
\hline interpersonal justice & 2.95 & 0.67 & & & & & & & \\
informational justice & 3.23 & 0.76 & $0.43^{* *}$ & - & & & & & \\
procedural justice & 2.87 & 0.64 & $0.24^{* *}$ & $0.7^{* *}$ & - & & & & \\
distributive justice & 3 & 0.77 & $0.18^{*}$ & $0.4^{* *}$ & $0.44^{* *}$ & - & & & \\
helping behavior & 3.68 & 0.79 & $0.42^{* *}$ & 0.02 & -0.06 & 0.1 & - & & \\
civic virtue & 3.58 & 0.75 & $0.34^{* *}$ & 0.13 & 0.1 & 0.12 & $0.77^{* *}$ & - & \\
sportsmanship & 3.64 & 0.88 & $0.38^{* *}$ & 0.15 & 0.11 & 0.17 & $0.74^{* *}$ & $0.77^{* *}$ & - \\
equity sensitivity & 4.56 & 1.38 & 0.09 & -0.05 & -0.06 & -0.05 & $0.28^{* *}$ & $0.27^{* *}$ & $0.23^{* *}$ \\
\hline
\end{tabular}

$\mathrm{N}=123 ;{ }^{*} \mathrm{p}<0.05 ; * * \mathrm{p}<0.01$

As shown in Table 2, among total sample, only interpersonal justice was positively and significantly correlated with helping behavior $(r=0.42, p<0.01)$, with civic virtue $(r=0.34, p<0.01)$ and with sportsmanship $(r=0.38$, $\mathrm{p}<0.05$ ). Informational, procedural and distributive justice has not significant correlation with helping behaviors, civic virtue, and sportsmanship. These findings only support first hypothesis (H1) about relationship between interpersonal justice and dimensions of OCBs. Equity sensitivity was positively and significantly correlated with helping behavior $(r=0.28, p<0.01)$, with civic virtue $(r=0.27, p<0.01)$ and with sportsmanship $(r=0.23, p<0$. $05)$. These findings support second hypothesis (H2) about relationship between equity sensitivity with dimensions of OCBs.

To test the third hypotheses, that is four dimensions of perceived organizational justice interactions with equity sensitivity would predict three dimensions of OCBs (i.e., helping behavior, civic virtue and sportsmanship), we followed the procedures recommended by Cohen, Cohen, West \& Aiken (2003). We mean-centered the four dimensions of perceived organizational justice, and equity sensitivity, and multiplied the two centered variables (informational justice $\times$ equity sensitivity, interpersonal justice $\times$ equity sensitivity, procedural justice $\times$ equity sensitivity, and distributive justice $\times$ equity sensitivity) to create a continuous interaction terms. Table 3 presents the result of the hierarchical moderated regression analysis.

In Table 3, a three-stage hierarchical moderated regression analysis was used to test the research hypothesis about the moderating effects of equity sensitivity (ES) on the relationship between four dimensions of perceived organizational justice with helping behavior, civic virtue and sportsmanship. In Model 1, each of four dimensions of perceived organizational justice was entered as predictor of helping behavior, civic virtue and sportsmanship. In Model 2, the equity sensitivity (ES) was entered as a predictor of helping behavior, civic virtue and sportsmanship. In Model 3, the multiplicative interaction term was entered. That is the two-way, cross-product terms between each of dimensions of perceived organizational justice with equity sensitivity (ES) were entered as predictors of helping behavior, civic virtue and sportsmanship. Our results (Table 3 ) show that equity sensitivity has been moderate the relationship between distributive justice and civic virtue $\left(\Delta R^{2}=0.052\right.$, $\Delta \mathrm{F}=7.26$ and $\mathrm{p}<0.01)$, the relationship between distributive justice and sportsmanship $\left(\Delta \mathrm{R}^{2}=0.042, \Delta \mathrm{F}=5.69\right.$ and $\mathrm{p}<0.05)$ and the relationship between procedural justice and sportsmanship $\left(\Delta \mathrm{R}^{2}=0.036, \Delta \mathrm{F}=4.6\right.$ and $\mathrm{p}<0.01$ ). These findings confirm partly $\mathrm{H} 2 \mathrm{a}$ and $\mathrm{H} 2 \mathrm{~b}$. To interpret the form of the moderated relationship, the interaction effect was plotted using the procedure suggested by Aiken and West (1991). Specifically, the regression lines of distributive and procedural justice on civic virtue and sportsmanship for high and low levels of moderating variable (equity sensitivity) were as shown in tables 4 and Figures 2 to 4 . Table 4 presents the correlation matrix for the research variables among entitleds, equity sensitives and benevolents groups. 
Table 3. The results of hierarchical moderated regression analysis

\begin{tabular}{|c|c|c|c|c|c|c|c|c|c|}
\hline & \multicolumn{3}{|c|}{ Helping behavior } & \multicolumn{3}{|c|}{ Civic virtue } & \multicolumn{3}{|c|}{ Sportsmanship } \\
\hline & Model1 & Model2 & Model3 & Model1 & Model2 & Model3 & Model1 & Model2 & Model3 \\
\hline & $\beta$ & $\beta$ & $\beta$ & $\beta$ & $\beta$ & $\beta$ & $\beta$ & $\beta$ & $\beta$ \\
\hline Informational justice(INFOJ) & 0.02 & 0.04 & 0.04 & 0.13 & 0.15 & 0.15 & 0.15 & 0.16 & 0.17 \\
\hline Equity sensitivity(ES) & - & $0.29 * *$ & $0.28 * *$ & - & $0.28 * *$ & $0.28 * *$ & - & $0.24 * *$ & $0.24 * *$ \\
\hline $\mathrm{INFOJ} \times \mathrm{ES}$ & - & - & -0.06 & - & - & -0.14 & - & - & -0.14 \\
\hline $\mathrm{R}^{2}$ or $\Delta \mathrm{R}^{2}$ & 0.000 & $0.082 * *$ & 0.004 & 0.018 & $0.081 * *$ & 0.02 & 0.023 & $0.06^{* *}$ & 0.021 \\
\hline $\mathrm{F}$ or $\Delta \mathrm{F}$ & 0.06 & $10.68 * *$ & 0.52 & 2.18 & $10.79 * *$ & 2.71 & 2.79 & $7.79 * *$ & 2.73 \\
\hline Interpersonal justice(INTEJ) & $0.42 * *$ & $0.4^{* *}$ & $0.38 * *$ & $0.34 * *$ & $0.31^{* *}$ & $0.32 * *$ & $0.33 * *$ & $0.36^{* *}$ & $0.36^{* *}$ \\
\hline Equity sensitivity(ES) & - & $0.25^{* *}$ & $0.26^{* *}$ & - & $0.25^{* *}$ & $0.24 * *$ & - & $0.2^{*}$ & $0.2 *$ \\
\hline INTEJ $\times$ ES & - & - & 0.08 & - & - & -0.028 & - & - & -0.003 \\
\hline $\mathrm{R}^{2}$ or $\Delta \mathrm{R}^{2}$ & $0.177 * *$ & $0.061 * *$ & 0.006 & $0.114^{* *}$ & $0.061 * *$ & 0.001 & $0144 * *$ & $0.041 *$ & 0.000 \\
\hline $\mathrm{F}$ or $\Delta \mathrm{F}$ & $26.05 * *$ & $9.58 * *$ & 0.88 & $15.56^{* *}$ & $8.88 * *$ & 0.11 & $20.42 * *$ & $5.97 *$ & 0.001 \\
\hline Procedural justice(PJ) & -0.06 & -0.04 & -0.03 & 0.1 & 0.11 & 0.13 & 0.11 & 0.12 & 0.14 \\
\hline Equity sensitivity(ES) & - & $0.28 * *$ & $0.29 * *$ & - & $0.28 * *$ & $0.3^{* *}$ & - & $0.24 * *$ & $0.27 * *$ \\
\hline $\mathrm{PJ} \times \mathrm{ES}$ & - & - & -0.07 & - & - & -0.15 & - & - & $-0.19 *$ \\
\hline $\mathrm{R}^{2}$ or $\Delta \mathrm{R}^{2}$ & 0.03 & $0.079 * *$ & 0.005 & 0.009 & $0.08 * *$ & 0.021 & 0.011 & 0.059 & $0.036 * *$ \\
\hline $\mathrm{F}$ or $\Delta \mathrm{F}$ & 0.39 & $10.35^{* *}$ & 0.68 & 1.12 & $10.55^{* *}$ & 2.82 & 1.38 & $7.56^{* *}$ & $4.6^{* *}$ \\
\hline Distributive justice (DJ) & 0.02 & 0.035 & 0.03 & 0.12 & 0.13 & 0.13 & 0.17 & $0.18^{*}$ & $0.17 *$ \\
\hline Equity sensitivity(ES) & - & $0.29 * *$ & $0.28 * *$ & - & $0.28 * *$ & $0.28 * *$ & - & $0.24 *$ & $0.24 * *$ \\
\hline $\mathrm{DJ} \times \mathrm{ES}$ & - & - & -0.12 & - & - & $-0.23 * *$ & - & - & $-0.2^{*}$ \\
\hline $\mathrm{R}^{2}$ or $\Delta \mathrm{R}^{2}$ & 0.000 & $0.082 * *$ & 0.012 & 0.014 & $0.08^{* *}$ & $0.052 * *$ & 0.029 & $0.06^{* *}$ & $0.042 *$ \\
\hline $\mathrm{F}$ or $\Delta \mathrm{F}$ & 0.05 & $10.67 * *$ & 1.64 & 1.74 & $10.66^{* *}$ & $7.26^{* *}$ & 3.59 & $7.89 * *$ & $5.69 *$ \\
\hline
\end{tabular}

Note. $* \mathrm{p}<0.05 * * \mathrm{p}<0.01$, Model $1=$ main effects of each of dimensions of perceived organizational justice, Model 2 = main effect of equity sensitivity, and Model 3 = interactive effects of each of dimensions of perceived organizational justice and equity sensitivity. 
Table 4. Correlation matrix for the research variables among three equity sensitivity group

\begin{tabular}{|c|c|c|c|c|c|c|c|}
\hline & 1 & 2 & 3 & 4 & 5 & 6 & 7 \\
\hline \multicolumn{8}{|c|}{ Entitleds group, $\mathrm{n}=20$} \\
\hline interpersonal justice & - & & & & & & \\
\hline informational justice & 0.26 & - & & & & & \\
\hline procedural justice & 0.15 & $0.6^{* *}$ & - & & & & \\
\hline distributive justice & 0.38 & $0.61 * *$ & 0.34 & - & & & \\
\hline helping behavior & 0.3 & 0.18 & -0.24 & 0.3 & - & & \\
\hline civic virtue & 0.33 & 0.22 & -0.1 & $0.49 * *$ & $0.8^{* *}$ & - & \\
\hline sportsmanship & $0.43^{*}$ & 0.24 & -0.07 & $0.39 *$ & $0.77 * *$ & $0.78 * *$ & - \\
\hline equity sensitivity & 0.05 & -0.06 & $-0.46^{*}$ & -0.15 & 0.36 & 0.28 & 0.24 \\
\hline \multicolumn{8}{|c|}{ Equity $\quad$ sensitives group, $\mathrm{n}=70$} \\
\hline interpersonal justice & - & & & & & & \\
\hline informational justice & $0.51 * *$ & - & & & & & \\
\hline procedural justice & 0.22 & $0.68 * *$ & - & & & & \\
\hline distributive justice & 0.06 & 0.17 & $0.46^{* *}$ & - & & & \\
\hline helping behavior & $0.41 * *$ & 0.09 & 0.02 & -0.06 & - & & \\
\hline civic virtue & $0.33^{* *}$ & $0.27 *$ & 0.23 & 0.01 & $0.71 * *$ & - & \\
\hline sportsmanship & $0.3^{*}$ & 0.2 & $0.26^{*}$ & 0.1 & $0.69^{* *}$ & $0.71^{* *}$ & - \\
\hline equity sensitivity & -0.06 & -0.11 & $-0.24 *$ & -0.16 & 0.02 & -0.07 & 0.01 \\
\hline \multicolumn{8}{|c|}{ Benevolents group, $\mathrm{n}=33$} \\
\hline interpersonal justice & - & & & & & & \\
\hline informational justice & $0.37 *$ & - & & & & & \\
\hline procedural justice & 0.28 & $0.78^{* *}$ & - & & & & \\
\hline distributive justice & 0.27 & $0.56^{*}$ & $0.51^{* *}$ & - & & & \\
\hline helping behavior & $0.46^{* *}$ & -0.18 & -0.19 & -0.08 & - & & \\
\hline civic virtue & 0.34 & -0.13 & -0.11 & -0.06 & $0.79 * *$ & - & \\
\hline sportsmanship & $0.49 * *$ & 0.02 & -0.12 & 0.07 & $0.77 * *$ & $0.74 * *$ & - \\
\hline equity sensitivity & 0.24 & 0.06 & 0.02 & -0.3 & 0.25 & 0.21 & $0.22 *$ \\
\hline
\end{tabular}

Note. $*$ p $<0.05 ; * * p<0.01$

As shown in Table 4, among entitled group, interpersonal justice was positively and significantly correlated with sportsmanship $(r=0.43, p<0.05)$, and distributive justice was positively and significantly correlated with civic virtue $(r=0.49, p<0.01)$, and with sportsmanship $(r=0.39, p<0.05)$. Also procedural justice was negatively and significantly correlated with equity sensitivity $(r=-0.46, p<0.05)$. As shown in Table 4 , among equity sensitives group, interpersonal justice was positively and significantly correlated with helping behavior $(\mathrm{r}=0.41$, $\mathrm{p}<0.01)$, with civic virtue $(\mathrm{r}=0.33, \mathrm{p}<0.01)$, and with sportsmanship $(\mathrm{r}=0.3, \mathrm{p}<0.05)$, informational justice was positively and significantly correlated with civic virtue $(\mathrm{r}=0.27, \mathrm{p}<0.05)$, and procedural justice was positively and significantly correlated with sportsmanship $(\mathrm{r}=0.26, \mathrm{p}<0.05)$, and negatively with equity sensitivity $(r=-0.24, p<0.05)$. As shown in Table 4, among benevolents group, only interpersonal justice was positively and significantly correlated with helping behavior $(r=0.46, p<0.01)$, and with sportsmanship $(r=$ $0.49, \mathrm{p}<0.01)$. 


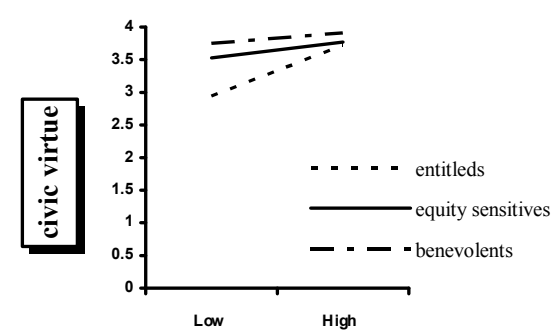

Distributive justice

Figure 2. Simple slopes of distributive justice on civic virtue for entitleds, equity sensitives and benevolents

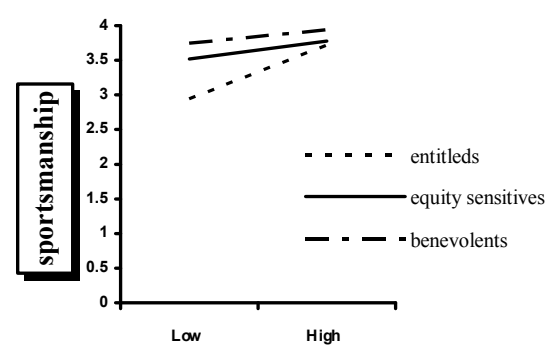

Distributive justice

Figure 3. Simple slopes of distributive justice on sportsmanship for entitleds, equity sensitives and benevolents

As predicted by $\mathrm{H} 2 \mathrm{a}$ partially, the moderation impact of equity sensitivity on the relationship between distributive justice with civic virtue and sportsmanship is stronger for entitled group (was significant, $r=0.49$, $p<0.01$ for civic virtue, and $r=0.39, p<0.05$ for sportsmanship) than equity sensitives (not significant, $r=0.01$, $p>0.05$ for civic virtue, and $r=0.1, p>0.05$ for sportsmanship) and benevolent groups (not significant, $r=-0.09$, $\mathrm{p}>0.05$ for civic virtue, and $\mathrm{r}=0.07, \mathrm{p}>0.05$ for sportsmanship).

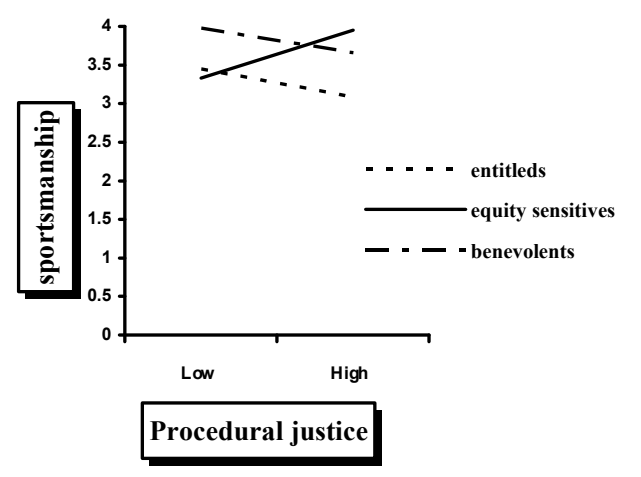

Figure 4. Simple slopes of procedural justice on sportsmanship for entitleds, equity sensitives and benevolents

Also as predicted by $\mathrm{H} 2 \mathrm{~b}$ partially, the moderation impact of equity sensitivity on the relationship between procedural justice with sportsmanship is stronger for equity sensitives group (was significant, $r=0.26, p<0.01$ ) than entitled (not significant, $r=-0.07, p<0.01$ ) and benevolent groups (not significant, $r=-0.12, p>0.05$ ).

\section{Discussion}

The purpose of the current research was to examine whether equity sensitivity had a moderating effect on the 
relationship between interpersonal, informational, procedural, and distributive justice and helping behavior, civic virtue, and sportsmanship. A basic premise of this paper was that equity sensitivity have moderating role on the relationship between perceived organizational justice and OCBs dimensions. As a rule, although some of the findings are more complex than hypothesized, the results partially support this basic argument. Findings revealed that among total sample group, interpersonal justice have a positive significant relationship with helping behavior, civic virtue, and sportsmanship, but informational, procedural, and distributive justice does not have any significant relationship with helping behavior, civic virtue, and sportsmanship. The findings of this study are not consistent with the findings of some previous researches. Many researchers have already proved the positive and strong relationship between some of perceived organizational justice, particularly procedural justice with OCB and their dimensions (Podsakoff et al, 2000; Cohen-Charash \& Spector, 2001; Williams et al, 2002). Meanwhile, some researchers were cautious about saying that procedural justice is the sole determinant of OCBs (Organ \& Moorman, 1993). One explanation for this non-finding is that informational, procedural, and distributive justice are generally perceptual variables which in many situations interact with the other dispositional or individual differences variables such as equity sensitivity (Blakely et al, 2005). In essence, to explain these findings, it could be said that dimensions of organizational justice might not have a direct effect on OCB dimensions, but it is likely to interact with dispositional construct such as equity sensitivity in predicting behavioral outcomes.

The second hypothesis, in which the equity sensitivity is positively related to helping behavior, civic virtue, and sportsmanship, was supported. The findings of this study are relatively consistent with the findings of Fok et al (1999), Kickul and Lester (2001), and Blakely et al. (2005) which reported a significant correlation between equity sensitivity and some of OCB dimensions. Additionally, the moderating analysis demonstrates how the equity sensitivity can alter some of the relationship between perceived organizational justice with civic virtue and sportsmanship. As found in this research, equity sensitivity has been moderated the relationship between distributive justice with civic virtue and sportsmanship and the relationship between procedural justice and sportsmanship, but it doesn't interact with informational and interpersonal justice when predicting OCBs. Primarily, our results consistent with findings of Blackely et al (2005) study, may present an insight why distributive justice have not predictive power for prediction of OCBs in many previous researches (Organ \& Moorman, 1993). In essence, it may be resulted from this truth that in the relationship between distributive justice and OCBs, many variables such as equity sensitivity play a moderator role (Blackely et al (2005). Theoretical, as Adam's equity theory (1965) suggests everyone tends to compare his/her perceived reward-to-effort ratio with others. If an under-reward situation appears, dissatisfaction may push employees to unpleasant performances. On the basis of equity sensitivity theory, benevolents have higher tolerance than equity sensitives and entitleds for under-reward outcomes. On the other hand, equity sensitives have a higher concern about equity norm and finally entitleds have a most concern for a lower input to outcome ratio (Hayes, 2005; Wheeler, 2007). The results of the current study are relatively consistent with the assertion of the equity sensitivity theory. On the basis of current research findings, if entitleds exposed in the perceived fairness towards their rewards (distributive justice), they were likely to give higher tending to civic virtue and sportsmanship. King et al (1993) suggested that entitleds primarily focus on outcomes or receipts with less regard for inputs or contributions. It is because of what leads to job satisfaction for entitleds is not so much absolute salary or other outcomes, but comparative salary. Blackely et al (2005) found that when organizational justice increase, entitleds showing a famous increase in OCBs. In current research recognized that with increasing distributive justice, the entitleds and no benevolents exhibit more civic virtue and sportsmanship. But, for procedural justice, findings revealed that when procedural justice increases, equity sensitives exhibit sportsmanship behaviors increasingly. Several possible explanations might account for the current research findings. First, in this research, OCBs and perceived organizational justice investigated in three and four dimensions respectively. In Blackely et al (2005) study, organizational justice investigated as a total scale. We have not found any researches which addressed the same issues. According to Young (2010), the omission of one or two dimensions of justice may lead researchers to overlook any significant relationship that would exist if the omitted dimensions were included. We believe that when organizational justice investigates totally and no in detailed dimensions, covering effect will occur. Covering effect point to effects which if constructs such as organizational justice investigate in detailed dimensions it will be achieved, but if constructs investigate totally, won't be achieved.

Second, there is some evidence which reveals that cultural difference is a potential factor which affects the relationships between variables at workplaces. James (1993), Yamaguchi (2003), and Allen et al (2005) concluded that cultural difference is a potential factor which impacts opinions, perception and behaviors of employees at workplaces. It should be said that there is no "right" way to deal with cultural difference about perceived organizational justice and equity sensitivity. In fact, our discussion presents an explanation for helping 
future researchers in minimizing the contradictory findings and maximizing the positive effects of cultural diversity. There are empirical evidences which reveal that levels of individualism-collectivism impact on behavioral reactions to the various situations. For example, James (1993) held that individualists follow equity regardless of the group membership of their interaction partner. With consider to the effects of cultural background on employees' opinions about fairness or rewards, punishments and procedures (James, 1993), it is likely that in current research, entitleds were more individualists (emphasis on individual goals, individual rights, autonomy, self-reliance, achievement orientation, and competitiveness) and preferred than benevolent for distributive justice, and on the other hand, equity sensitives were less individualists and preferred than entitleds and benevolent for procedural justice. Therefore, it is that, among participants of this research, equity preferences and no equity sensitivity are major variables which affect the relationship between distributive justice with civic virtue and sportsmanship and the relationship between procedural justice and sportsmanship. We believe that in some cultures, as in Iran, among some groups (such as entitleds or equity sensitivis) there is a high need for some of organizational justice dimensions such as distributive or procedural justice (Golparvar \& Rafizadeh, 2009, 2010). For this, the equity sensitivity could moderate the relationship between special dimensions of perceived organizational justice (i.e., distributive justice) with negative or positive behaviors at workplaces. Also, in accordance with equity sensitivity theory, we believe that each of three equity sensitivity groups likely have special preferences for special dimensions of organizational justice (i.e., entitleds for distributive justice and equity sensitives for procedural justice). Another possible explanation is that, in current research, entitleds viewed the distributive justice as a means to an end which minority brings them just outcomes and perhaps equity sensitives, because they are satisfied if, and only if, they get a balanced actual effort and reward ratio (Lok, 2007), feel that procedural justice will ultimately brings them complete fair outcomes. In other words, entitleds viewed distributive justice as tools to increase the probability of what achieved them to fair outcomes rather than improbable over-reward outcomes. Finally, we emphasized that the moderating effects of equity sensitivity will depend on the national and organizational culture of the research sample group. This study relatively supports the proposition that national and organizational culture affect the propositions of equity sensitivity theory about the relationship between organizational justice and OCBs.

\section{Research and Theory Implications}

The findings of current research have important implications for the theory and future research. This study highlights various areas where additional research would be useful. First, further examinations of how equity sensitivity interacts with perceived organizational justice on predicting OCBs and their dimensions in other countries are needed. Our findings suggest that moderating effects of equity sensitivity in the relationship between organizational justice and behavioral outcomes at workplaces may be related to the organizational and national structure and culture. A useful path for further research is to examine the effects of cultural values on the relationship between perceived organizational justice and equity sensitivity with dimensions of OCB. Second, it would be useful to take a detailed attention at the different effects that equity sensitivity have on job satisfaction, organizational commitment and job involvement and on behavioral responses (positive one such as OCBs and negative one such as deviant behaviors) separately. Future studies should also continue to examine how equity sensitivity interacts with other perceptual variable such as psychological contract to influence different types of negative and positive behaviors. Also, a useful path for further research is to examine other measures of OCBs and measures of other behaviors such as innovative behaviors and so on. Finally, on the basis of their organization conditions about distributive and less procedural justice, organizations should consider equity sensitivity as an important employee selection test. Therefore, future studies should consider how to develop equity sensitivity as a hiring instrument.

\section{Limitations}

This study does have some limitations. First, a common method variance - a methodological problem that is defined as a variance that is attributed to multiple constructs being measured using the same method (i.e. self-report questionnaires) rather than actual covariance between the constructs (Podsakoff, MacKenzie, Lee and Podsakoff, 2003), could account for the observed relationships among the variables. Since all the data in the current study were collected using self-report Likert-type questionnaires, it is possible that the observed relationships between the constructs (perceived organizational justice, equity sensitivity, and OCB dimensions) were in some way altered by the common measurement method. Second, the sample size in current research is small. Larger sample sizes for studying about the moderating effects of equity sensitivity on the relationship between dimensions of organizational justice and OCB are necessary for future studies. Blackely et al (2005) believed that a larger sample size would allow the dimensions of justice to be examined separately and accurately. Third, the trichotomizing equity sensitivity has been criticized for several reasons, for calling into 
question its robustness as a measurement of ES. Sauley and Bedeian (2000) have criticized measurement of ES and developed the Equity Preference Questionnaire (EPQ) to address these concerns. Also, Yamaguchi (2003) contended that a forced distribution measurement is not appropriate for measuring psychological states. For this, in future researches, researcher could use Equity Preference Questionnaire (EPQ) in their studies. Fourth, the current study was cross-sectional; therefore interpretation of causality about our findings is not true. Fifth, our data were collected in Iran and generalizing it to other cultures should be done with caution. Finally, since this study used only the self- report of OCBs, future study should consider the use of co-workers or supervisor evaluation of OCBs and reexamine the moderating effects of equity sensitivity on the relationship between dimensions of perceived organizational justice and OCB dimensions.

\section{References}

Ackfeldt, A. L., \& Coote, L.V. (2005). A study of organizational citizenship behaviors in retail setting. Journal of Business Research, 58, 151-159. http://dx.doi.org/10.1016/S0148-2963(03)00110-3

Adams, J. S. (1965). Inequity in social exchange. In L. Berkowitz (Eds.), Advances in experimental social psychology (pp.267-299). New York: Academic Press.

Allen, R. S., Biderman, M. D., \& White, C. S. (2004). Emotional intelligence and its relation to equity sensitivity and response to under-reward situations. The Journal of Behavioral and Applied Management, 5(2), 114-136.

Allen, R. S., Takeda, M., \& White, C. S. (2005). Cross-cultural equity sensitivity: a test of differences between the United States and Japan. Journal of Managerial Psychology, 20(8), 641-662. http://dx.doi.org/10.1108/02683940510631426

Asgari, A., Silong, A. D., Ahmad, A., \& Samah, B. A. (2008). The relationship between transformational leadership behaviors, organizational justice, leader-member exchange, perceived organizational support, trust in management and organizational citizenship behaviors. European Journal of Scientific Research, 23(2), 227-242.

Blackely, G. L., Andrews, M. C., \& Moorman, R. H. (2005). The moderating effects of equity sensitivity on the relationship between organizational justice and organizational citizenship behaviors. Journal of Business and Psychology, 20(2), 259-273. http://dx.doi.org/10.1177/1046496408326575

Brislin, R. W. (1980). Translation and content analysis of oral and written material. In H. C. Triandis \& J. W. Berry (Eds.), Handbook of cross-cultural psychology (Vol. 2 pp. 389 - 444). Boston: Allyn and Bacon.

Chien, M. H. (1988). A study to Improve organizational citizenship behaviors. Management, 21, 1364-1367.

Cohen-charash, Y., \& Spector, P. E. (2001). The role of justice in organizations: A meta-analysis. Organizational Behavior and Human Decision Processes, 86(2), 278-321.

Cohen, J., Cohen, P. West, S. G., \& Aiken, L. S. (2003). Applied multiple regression/correlation analysis for the behavioral sciences.(3rd ed.). Mahwah, New Jersey, Lawrence Erlbaum Associations.

Colquitt, J. A. (2001). On the dimensionality of organizational justice: A construct validation of a measure. Journal of Applied Psychology, 86, 386-400. http://dx.doi.org/10.1037//0021-9010.86.3.386

Colquitt, J. A., Greenberg, J., \& Zapata-Phelan, C. P. (2005). What is organizational justice: An historical overview. In J. Greenberg \& J. A. Colquitt (Eds.), Handbook of organizational justice (pp. 3-58). Mahwah, NJ: Lawrence Erlbaum Associates.

Eisenberger, R., Fasolo, P., \& Davis-LaMastro, V. (1990). Perceived organizational support and employee diligence, commitment, and innovation. Journal of Applied Psychology, 75, 51-59. http://dx.doi.org/10.1037/0021-9010.75.1.51

Fischer, R., \& Smith, P. B. (2003). Reward allocation and culture: A meta-Analysis. Journal of Cross-Cultural Psychology, 34 (3), 251-268. http://dx.doi.org/10.1177/0022022103251753

Farh, J. L., Hacket, R. D., \& Liang, J. (2007). Individual-level cultural values as moderators of perceived organizational support-employee outcome relationships in China: Comparing the effects of power distance and traditionality. Academy of Management Journal, 50, 715-729.

Fok, L., Hartman, S, Patti, A., \& Razek, J. (1999). The relationships between equity sensitivity, growth need strength, organizational citizenship behavior, and perceived outcomes in the quality environment: A study of accounting professionals. Journal of Social Behavior and Personality, 15, 99-120. 
Foote, D. A., \& Harmon, S. (2006). Measuring equity sensitivity. Journal of Managerial Psychology, 21(2), 90-108. http://dx.doi.org/10.1108/02683940610650721

Golparvar, M., \& Rafizadeh, P. (2009). Promotion model of organizational citizenship behavior through job attitudes, professional development, leadership support and empowerment. Quarterly Journal of Basirat in Management, 16(44), 27-45.

Golparvar, M., \& Rafizadeh, P. (2010). The role of justice on attitude toward organization and satisfaction with complaint handling. Ethics in Science and Technology, 4(3/4), 54 - 65.

Hayes, S. C. (2005). The relationship between the symbolic meaning of money and referent choice under situations of inequity. Unpublished Doctoral Dissertation, Graduate School of the University of Maryland, College Park.

Hollensbe, E. E., Khazanchi, S., \& Masterson, S. S. (2008). How do I assess if my supervisor and organization are fair? Identifying the rules underlying entity-based justice perceptions. Academy of Management Journal, 51, 1099-1116. http://dx.doi.org/10.5465/AMJ.2008.35732600

Huseman, R., Hatfield, J., \& Miles, E. (1985). Test for individual perceptions of job equity: Some preliminary findings. Perceptual and Motor Skills, 61, 1055-1064. http://dx.doi.org/10.2466/pms.1985.61.3f.1055

Huseman, R., Hatfield, J., \& Miles, E. (1987). A new perspective on equity theory: The equity sensitivity construct. The Academy of Management Review, 12, 222-234. http://dx.doi.org/10.2307/258531

Ishak, N. A., \& Alam, S. S. (2009). The effects of leader-member exchange on organizational justice and organizational citizenship behavior: Empirical study. European Journal of Social Sciences, 8(2), 324-334.

James, K. (1993). The social context of organizational justice: Cultural, intergroup, and structural effects on justice behaviors and perceptions. In R. Cropanzano (Eds.), Justice in the workplace: Approaching fairness in HRM (pp. 21-50). Hillsdale, NJ: Lawrence Erlbaum.

Kickul, J., \& Lester, S. W. (2001). Broken promises: Equity sensitivity as a moderator between psychological contract breach and employee attitudes and behavior. Journal of Business and Psychology, 16, 191-217. http://dx.doi.org/10.1023/A:1011105132252

King, W., \& Miles, E. (1994). The measurement of equity sensitivity. Journal of Occupational and Organizational Psychology, 67, 133-142. http://dx.doi.org/10.1111/j.2044-8325.1994.tb00556.x

King, W., Miles, E., \& Day, D. (1993). A test and refinement of the equity sensitivity construct. Journal of Organizational Behavior, 14, 301-317. http://dx.doi.org/10.1002/job.4030140403

Konovsky, M. A., \& Organ, D. W. (1996). Dispositional and contextual determinants of organizational citizenship behavior. Journal of Organizational Behavior, 17, 253-266.

Lievens, F., \& Anseel, F. (2004). Confirmatory factor analysis and invariance of an organizational citizenship behavior measure across samples in a Dutch-speaking context. Journal of Occupational and Organizational Psychology, 77, 299-306. http://dx.doi.org/10.1348/0963179041752727

Lok, C. K. (2007). Equity sensitivity as a moderator between equity perception and pay satisfaction. Unpublished Bachelor Thesis, Hong Kong Baptist University.

Miao, R., \& Kim, H. G. (2010). Perceived organizational support, job satisfaction and employee performance: An Chinese empirical study. Journal of Service Science \& Management, 3, 257-264. http://dx.doi.org/10.4236/jssm.2010.32032

Moorman, R. H. (1991). Relationship between organizational justice and organizational citizenship behavior: Do fairness perceptions influence employee citizenship? Journal of Applied Psychology, 76, 845-855. http://dx.doi.org/10.1037/0021-9010.76.6.845

Morrison, E. W., \& Robinson, S. L. (1997). When employees feel betrayed: A model of how psychological contract violation develops. Academy of Management Review, 22(1), 226-256.

Organ, D. W., \& Konovsky, M. (1989). Cognitive versus affective determinants of organizational citizenship behavior. Journal of Applied Psychology, 74(1), 157- 64. http://dx.doi.org/10.1037/0021-9010.74.1.157

Organ, D. W., \& Moorman, R. H. (1993). Fairness and organizational citizenship behavior: What are the connections? Social Justice Research, 6, 5-18. http://dx.doi.org/10.1007/BF01048730

Organ, D. W., \& Ryan, K. (1995). A meta-analytic review of attitudinal and dispositional predictors of $\begin{array}{llll}\text { organizational citizenship behavior. Personnel Psychology, 48, } & \text { 775-802. }\end{array}$ 
http://dx.doi.org/10.1111/j.1744-6570.1995.tb01781.x

Paille, P. (2009). Assessing organizational citizenship behavior in the French Context: Evidence for the Four-Dimension Model. The Journal of Psychology, 143(2), 133-147. http://dx.doi.org/10.3200/JRLP.143.2.133-146

Podsakoff, P. M., MacKenzie, S. B., Lee, J. Y., \& Podsakoff, N. P. (2003). Common method biases in behavioral research: A critical review of the literature and recommended remedies. Journal of Applied Psychology, 88(5), 879-903. http://dx.doi.org/10.1037/0021-9010.88.5.879

Podsakoff, P. M., MacKenzie, S. B., Paine, J. B., \& Bachrach, D.G. (2000). Organizational citizenship behavior: A critical review of the theoretical and empirical literature and suggestions for future research. Journal of Management, 26, 513-563. http://dx.doi.org/10.1177/014920630002600307

Roch, S. G., \& Shanock, L. R. (2006). Organizational justice in an exchange framework: Clarifying organizational justice distinctions. Journal of Management, 32, 299-322. http://dx.doi.org/10.1177/0149206305280115

Restubog, S. L. D., Bordia, P., \& Tang, R. L. (2007). Behavioral outcomes of psychological contract breach in a non-western culture: the moderating role of equity sensitivity. British Journal of Management, 18, 376-386. http://dx.doi.org/10.1111/j.1467-8551.2007.00531.x

Sauley, K. S., \& Bedeian, A. G. (2000). Equity sensitivity: Construction of a measure and examination of its $\begin{array}{llll}\text { psychometric properties. Journal of } & \text { 85-910. }\end{array}$ http://dx.doi.org/10.1177/014920630002600507

Wheeler, K. G. (2007). Empirical comparison of equity preference questionnaire and equity sensitivity instrument in relation to work outcome preferences. Psychological Reports, 100, 955-962. http://dx.doi.org/10.2466/pr0.100.3.955-962

Williams, S., Pitre, R., \& Zainuba, M. (2002). Justice and organizational citizenship behavior intentions: fair rewards versus fair treatment. The Journal of Social Psychology, 142(1), 33-44. http://dx.doi.org/10.1080/00224540209603883

Yamaguchi, I. (2003). The relationship among individual differences, needs and equity sensitivity. Journal of Managerial Psychology, 18(4), 324-344. http://dx.doi.org/10.1108/02683940310473082

Young, L. D. (2010). Is organizational justice enough to promote citizenship behavior at work? A retest in Korea. European Journal of Scientific Research, 45 (4), 637-648. 